\title{
Come and say what you think: reducing employees' self-censorship through procedural and interpersonal justice
}

\author{
Krystyna Adamska (DD A,B,E,F, Pawet furek (DD $C, D, E$ \\ Institute of Psychology, University of Gdansk, Gdansk, Poland
}

\section{BACKGROUND}

Self-censorship in an organization may be defined as a conscious decision by employees to refrain from expressing opinions, criticism or suggestions in situations of perceived irregularities. There are at least two reasons for this decision: firstly, the fear that speaking up would prompt negative consequences, and secondly, the belief that it would not bring about a change in the situation. Procedural justice in an organization may encourage employees to limit that silence, thereby diminishing fear and undermining the belief that change is impossible.

\section{PARTICIPANTS AND PROCEDURE}

A set of three studies (total number of participants $N=710$ ) was conducted in order to determine whether procedural justice predicts self-censorship and also to define the role of interpersonal justice in this relationship. It was assumed that procedural justice, while useful in the formation of an impartial and rigid legal system within an organization, is constrained by its disregard for personal relations.
RESULTS

It was found that when employees perceive a work environment as providing influence over procedures, they declare less self-censorship motivated by fear and resignation. In high interpersonal justice conditions the role of procedural justice in predicting employee self-censorship as well as employee silence beliefs increases.

\section{CONCLUSIONS}

Both fair treatment of all employees and the contextual and need-centered nature of such treatment should be integrated if self-censorship is to be reduced. The results confirm this conclusion for self-censorship (decision) and employee silence beliefs (belief that relations within the organization do not encourage people to speak up).

\section{KEY WORDS}

self-censorship; procedural justice; interpersonal justice; employee silence beliefs; acquiescent silence; quiescent silence

CORResPonding AUthor - Krystyna Adamska, Ph.D., Institute of Psychology, University of Gdansk, 4 Bażyńskiego Str., 80-309 Gdansk, Poland, e-mail: krystyna.adamska@ug.edu.pl

AUthors' CONTRIBUtion - A: Study design - B: Data collection - C: Statistical analysis - D: Data interpretation .

E: Manuscript preparation · F: Literature search · G: Funds collection

TO CITE THIS ARTICLE - Adamska, K., \& Jurek, P. (2021). Come and say what you think: reducing employees'

self-censorship through procedural and interpersonal justice. Current Issues in Personality Psychology, 9(4), 328-340.

RECEIVED 28.09.2020 · REVIEWED 17.03.2021 · ACCEPTED 25.07.2021 · PUBLISHED 29.10.2021 


\section{BACKGROUND}

The free expression of ideas, judgments and opinions opens up the possibility of sharing knowledge and at the same time constitutes the essence of regulating relations in a democratic society (Bar-Tal et al., 2017; Gilligan, 2006). Sharing knowledge in an organization, giving feedback, pointing to problems and suggesting solutions constitute communication aimed at continuous development, based on the predetermined goals and standards (Tushman \& Nadler, 1978; Wiener, 1950). This desirable process of open communication clashes with the informal side of social life in an organization, often taking the form of a game in which some win at the expense of others (Argyris \& Schon, 1978). As a result, communication openness which is beneficial to the process of achieving organizational goals may be undesirable from the perspective of the interests of the individual who censors his or her own speech (Adamska, 2017). That leads to employee silence (Morrison \& Milliken, 2000; Morrison, 2014; Knoll et al., 2016).

Self-censorship protects against the alleged consequences of open communication, but concerns about speaking are not the only reason why an employee remains silent (Zill et al., 2020). When attempts to share information about irregularities observed or about proposals for change end in failure, an employee may become convinced that speaking out is pointless. Both the fear of the consequences of taking the floor and a lack of belief in the sense of taking the floor in the first place are based on experiences derived from direct contact with a superior, HR department, senior superior or colleague. By observing behaviors of others, an employee assimilates informal rules of behaviors, among them the rules of speaking: when, what and with whom (Detert \& Edmondson 2011; Knoll et al., 2021; Nechanska et al., 2020). While the social rules of speaking are reflected in employee silence beliefs (Adamska \& Retowski, 2012), the individual experiences lead to self-censorship (Knoll \& van Dick, 2013).

There are at least two ways of limiting self-censorship: formal, through fair procedures; and informal, through direct influence in the acts of communication (Wilkinson \& Dundon, 2017). These two factors are rooted in two different kinds of ethics which are ethics of justice and relational ethics. The ethics of justice is impartial and free from the impact of current circumstances (Rawls, 1999). The relational ethics is contextual and underlines the role that emotions play in moral judgments and decisions (Gilligan, 1982; Hamington, 2019). Studies of factors that limit self-censorship in organizations have been conducted separately for formal procedures (Tangirala \& Ramanujam, 2008) and quality of relations (Gao et al., 2011; Hirak et al., 2012). However, as the reflection on the ethics of justice and relational ethics shows (Allen, 2013), two factors can be mutually complementary in their influence on self-censorship. In organizational studies ethics of justice is represented by procedural justice while relational ethics is represented by interpersonal justice (Colquitt, 2001).

The aim of the research presented in the article is to establish the relationship between procedural justice and employee self-censorship and to assess the importance of interpersonal justice as regards the negative effect of procedural justice on employee self-censorship. Three hypotheses were formulated: Hypothesis 1: Procedural justice predicts a reduction in employee self-censorship; Hypothesis 2: The reduction of employee self-censorship under the influence of procedural justice increases in high interpersonal justice conditions, and Hypothesis 3: The reduction of employee silence beliefs under the influence of procedural justice increases under conditions of high interpersonal justice. Both the decision to remain silent (self-censorship) and the belief that no climate exists for speaking (employee silence beliefs) are associated with a fear of the consequences of speaking or doubt over the effectiveness of speaking (acquiescent and quiescent silence).

\section{SELF-CENSORSHIP AND EMPLOYEE SILENCE BELIEFS}

Self-censorship is a strategy developed for coping with others. The belief that 'it is better to be silent' may have its roots in early childhood, when the idea of voice is vaguely identified as activity and influence. Punishment for being 'too visible - too loud' or failure to receive a response to that voice bolsters this belief. Silence may demonstrate its strategic value in organizations, where the decision to withdraw from voicing in situations perceived as ripe for change for moral or pragmatic reasons (with no formal obstacles to voice) may be shaped by organizational experiences (Morrison \& Milliken, 2000). Self-censorship, a kind of deactivation (Pinder \& Harlos, 2001), is exacerbated by individual characteristics such as neuroticism or agreeableness (LePine \& Van Dyne, 2001), relations between managers and subordinates, or employeremployee relations (Tangirala \& Ramanujam, 2008). In the long run, self-censorship has a detrimental effect on individual well-being (Beer \& Eisenstat, 2000; Tahmasebi et al., 2013) and may damage group efficiency (Cortina \& Magley, 2003; Perlow \& Williams, 2003).

There are at least two causes of self-censorship, understood as non-participation: resignation and fear of consequences. Resignation occurs when the employee's voice goes unanswered, since there is no one, particularly no powerholders, to listen, and all endeavors to gain influence on a critically perceived situation prove futile. This kind of decision to selfcensor leads to acquiescent silence, that is passive ac- 
ceptance of the status quo (Pinder \& Harlos, 2001). As a result an employee does not consider alternatives to the current situation. When self-censorship is motivated by fear that voicing may provoke negative responses in recipients, then it takes the form of quiescent silence (Van Dyne et al., 2003). In this case the decision not to speak up is defensive in its character, proactive and consciously driven due to the fact of consideration of negative outcomes. The process of making a decision not to speak is accompanied by negative emotions, which are rooted in childhood experiences with authority (Kish-Gephart et al., 2009) and related to generalized reluctance to deliver negative news to others (Lee, 1993).

Unlike self-censorship, which is a decision by employees to refrain from expressing opinions, criticism or suggestions in situations of perceived irregularities, silence beliefs reflect informal rules of speaking assimilated by a person in an organization in the process of learning effective tactics of communication (particularly in the first stage of employment) (Argyris \& Schon, 1978). By observing social incidents an employee recognizes those social settings in which speaking up is futile (acquiescent silence beliefs) and those in which speaking threatens one's own interests (quiescent silence beliefs) (Adamska \& Retowski, 2012). Silence beliefs are shared by employees who may even discuss when, what and with whom it is wise and effective to exchange information and opinions (Detert \& Edmondson, 2011; Knoll et al., 2021; Morrison \& Milliken, 2000; Nechanska et al., 2020).

\section{THE ETHICS OF JUSTICE AND SELF-CENSORSHIP}

The ethics of justice defines a mode of making decisions in terms of universal principles and rules (Botes, 2001). The final decision is to be impartial, possible to verify and based on the premise of equality: everyone should be treated the same (Rawls, 1999). The rational process of deciding requires the use of procedures, set out in detail and known to everyone. The immanent part of procedural justice is the possibility to voice objections or innovative ideas, through which influence on the decisional process can be achieved (Folger, 1977; Thibaut \& Walker, 1975). The opportunity to openly express an opinion lies at the heart not only of psychological health (Judge \& Colquitt, 2004) but at the very idea of democracy (Rawls, 1999). It was demonstrated in organizational studies that the reluctance to speak is reduced when procedures are respected within an organization and when they apply to everyone, regardless of position, but also when decisions are reached on the basis of these procedures (Donaghey et al., 2011). Also qualitative studies have shown that perceived fairness at work is important for enhancing the proneness to speak up (Pinder \& Harlos, 2001), and research by
Tangirala and Ramanujam (2008), where employees were less silent when they perceived a high level of procedural justice, lends direct support for the procedural justice-self-censorship link.

The psychological basis of fair procedures lies in the individual self (van Prooijen \& Zwenk, 2008), so the role of procedural fairness in reducing selfcensorship could be explained by reference to selfevaluation processes, activated in the context of potential conflict as a result of challenging relations by openly stated opinions and criticism. This is in line with Rawl's (1999) assertion that self-respect, with its twin aspects of self-esteem and self-efficacy, is supported by the concept of justice as fairness. The studies confirm this: when the self is salient, fairness issues become more important (Sedikides \& Gregg, 2008; Skitka, 2003; Tyler \& Lind, 1992; Van den Bos \& Lind, 2010). Brebels et al. (2013) conducted a study that showed that self-rumination enhances the influence of fair or unfair procedures on the predilection for future interactions. These results were interpreted in the context of the assumption that procedural fairness serves the purpose of reducing uncertainty (Blader \& Tyler, 2009; De Cremer \& Sedikides, 2005).

The experience of uncertainty intensifies in the process of communication with supervisors (Overback et al., 2006), and indeed the influence of a superior on employee self-censorship has been the subject of many studies. Exercising procedural justice in the manager's daily contacts with the subordinates, such as communicating aims, and administering and controlling the processes of achieving them, significantly modifies self-censorship (Donaghey et al., 2011). This supports the claim that self-censorship may be reduced through formal mechanisms of voice (Wilkinson \& Dundon, 2017), mechanisms which themselves are effective particularly when taken seriously by managers (Wilkinson et al., 2010).

Hypothesis 1: Procedural justice predicts reduction of employee self-censorship.

Relational ethics and self-censorship. Yet, Sandel (1998) points to the fact that the idea of a non-attached person governed by impartial justice does not harmonize with the social embeddedness of the self. The social approach to justice in organizations has led to the distinction of interpersonal justice, founded on the notion of being respected (Greenberg, 1993). Judgment of interpersonal justice is particularly subject to the intensity of the need to belong to a certain social category (Wenzel, 2000). This, in turn, is modified by status: the lower the status, the greater the meaning attached to interpersonal justice (Chen et al., 2003). The importance of interpersonal justice increases with the activation of the interdependent self, which is characterized by a sense of connectedness with others and by due attention to one's role within in-groups (Holmvall \& Bobocel, 2008). This explains why self-censorship motivated by fear and resignation diminishes if the 
leader is available to subordinates and genuinely appreciates their voices (Hirak et al., 2012). Appreciation may in turn modify shame, an emotion which, according to Creed et al. (2014), upholds self-censorship.

This positive effect of interpersonal justice can be interpreted in the broader theoretical context of relational ethics, as constituted by the specific characteristics of interaction between individuals, in which they are considered worthy of implementation and reward (Metz \& Miller, 2016). Mutual respect (the means to mitigate power differentials), engagement and embodied knowledge become the most important features and are closely linked to the responsibility for another person (Pollard, 2015). According to Hamington (2011), a culture of care fosters fundamental respect in an organization and engages intellectual inquiry: "A corporate culture of care does not suggest that members of the organization must become friends or develop strong relationships. It does suggest that people are attentive to one another as part of a willingness to grow" (Hamington, 2011, p. 245). For Gilligan (2006), the pre-eminent representative of the ethics of care, the voicing of ideas, beliefs, expectations and needs is commensurate with the quality of relations.

Relations with a supervisor are very often evaluated through the lens of relational ethics, exemplified by interpersonal justice (Cohen-Charash \& Spector, 2001; Colquitt et al., 2001), which is rated highly if an employee is treated with courtesy and dignity, and without improper remarks or comments (Colquitt \& Rodell, 2015). Employees who do not feel respected by their leader display more behaviors that conflict with the interests of the organization (LeRoy et al., 2012), and the relationship is mediated by negative emotions. By contrast, those who receive respect and care are inclined to exceed the basic requirements of the job and contribute to the effectiveness of the entire organization, even though their behaviors are not formally rewarded (Rego \& Pina a Cunha, 2010). This proactivity and engagement is also observed in the field of communication: the unwillingness to share information drops if behaviors of the supervisor convey a signal of concern for the high quality of relations (Gao et al., 2011; Hirak et al., 2012). On the other hand, employees' self-censorship rises when a supervisor displays aversion to those who speak up (Fast et al., 2014).

The importance of relational ethics in limiting selfcensorship is, in the opinion of Donaghey et al. (2011), the result of the managers' interpretation of voice (not institutionalized voicing rules). Also Bauman and Skitka (2009) point to the situations of strong moral disagreement, in which procedural fairness loses its effects. It does not mean that the authors diminish the role of procedural justice. On the contrary, though caring is an appropriate mechanism through which individuals interact in the majority of situations, it excludes the possibility of impartiality so important in complex social settings (Rumsey, 1997). It could be concluded that both kinds of ethics - the ethics of justice (procedural justice) and relational ethics (interpersonal justice) - are important factors of limiting self-censorship and silence beliefs and relational ethics strengthens the effect of the ethics of justice.

Hypothesis 2: The reduction of employee self-censorship under the influence of procedural justice increases in high interpersonal justice conditions.

Hypothesis 3: The reduction of employee silence beliefs under the influence of procedural justice increases in high interpersonal justice conditions.

\section{PRESENT STUDY}

The present study investigates the link between procedural justice, interpersonal justice and selfcensorship in organizations. The general view of the relations between employer (as well as employer's representatives) and employee may take the form of procedural justice judgment. The employee is asked about the scope of influence on the decisions made in the organization, voice opportunity and the consistency with which the decisions are implemented. Transparent rules, to which all employees are subjected, eliminate favoritism and offer a formal path for grievances. This may influence the decision to break self-censorship, reducing fear in the process and ensuring that that voice is heard. This does not, however, necessarily mean that personal perceptions, attributions (the processes by which individuals explain the causes of behaviors and events), informal norms and mutual interests are governed by procedural justice. Procedural justice as a signal of an employer's positive intentions may be too weak to convince employees that self-censorship is not the proper reaction to perceived problems and difficult situations. Due respect and care may amplify the signal by conveying the message that the addressee is important and that their needs and feelings are considered. Therefore we expect that: Hypothesis 1: Procedural justice predicts reduction of employee self-censorship (Study 1); $\mathrm{Hy}$ pothesis 2: The reduction of employee self-censorship under the influence of procedural justice increases in high interpersonal justice conditions (Study 2), and Hypothesis 3: The reduction of employee silence beliefs under the influence of procedural justice increases in high interpersonal justice conditions (Study 3).

\section{STUDY 1}

\section{PARTICIPANTS AND PROCEDURE}

The study participants were 161 employees (80 female and 81 male) from a variety of industries, 70 employed in managerial and 91 in non-managerial positions. The participants were aged between 
19 and $57(M=35.56, S D=8.47)$, and average work experience in the organization equaled 3.95 years $(S D=4.78)$. Participants in MBA studies completed questionnaires during the class activity of a Human Resources Management course.

\section{MEASURES}

Procedural justice. We used the Polish adaptation of the seven-item scale developed by Colquitt (2001) to measure procedural justice (Retowski et al., 2017). Participants answered the questions about ways to receive pay, benefits, evaluations or promotions procedure. The scale included items such as "Are you able to express your views and feelings during those procedures?" and "Are those procedures applied consistently?". Respondents used a five-point scale from 1 (to a very small extent) to 5 (to a very large extent) to rate the items.

Employee self-censorship. In order to measure employee self-censorship, two subscales (quiescent and acquiescent silence) were used, as adapted into Polish by Adamska and Jurek (2017) from the Four Forms of Employee Silence Scale developed by Knoll and van Dick (2013). Each of these subscales includes three items describing reasons why participants withhold information regarding problems noticed in the workplace, e.g. "...because of fear of negative consequences” (quiescent silence), “...because nothing will change, anyway” (acquiescent silence). Participants used a seven-point scale from 1 (never) to 7 (very often) to rate all items. A measure of employee silence was composed from these two subscales.

\section{RESULTS}

Table 1 shows the descriptive statistics and intercorrelations for the variables examined in Study 1. Scale reliability in the current study was assessed using Cronbach's $\alpha$. The reliability coefficients for each scale are shown on the diagonal.

A simple linear regression was calculated to predict quiescent and acquiescent silence based on pro- cedural justice. As expected, procedural justice significantly predicted both the quiescent silence scores, $b=-.61,95 \%$ CI $[-.86,-.36], \beta=-.35, t(159)=-4.74$, $p<.001$, and the acquiescent silence scores, $b=-.79$, $95 \%$ CI $[-1.51,-.53], \beta=-.42, t(159)=-5.80, p<.001$. Procedural justice explained a significant proportion of variance in quiescent silence scores, $R^{2}=.12$, $F(1,159)=22.50, p<.001$, and in acquiescent silence scores, $R^{2}=.17, F(1,159)=33.58, p<.001$.

In confirming Hypothesis 1 , it was found that procedural justice predicts reduction of employee self-censorship. It does mean that a work environment that offers influence over procedures, opportunities for voice and appeals against outcomes plays an important role in reducing self-censorship within the organization. The ethics of justice upheld by the organization contributes to reducing the decision to withdraw from an active attempt to change an undesirable situation. The effect of procedural justice on self-censorship is significant both when the decision to remain silent is motivated by resignation (acquiescent silence) and when it is accompanied by fear of the consequences (quiescent silence). Study 1 confirmed the relation between procedural justice and self-censorship but did not consider the role of interpersonal justice as a manifestation of relational ethics. Study 2 was conducted to test the possibility that in high interpersonal justice conditions the reduction of employee self-censorship under the influence of procedural justice increases.

\section{STUDY 2}

\section{PARTICIPANTS AND PROCEDURE}

The study participants were 163 employees (136 female and 27 male) from a variety of industries, 74 employed in managerial and 89 in non-managerial positions. The participants were aged between 22 and $60(M=37.56, S D=9.38)$ with an average work experience in the organization of 15.42 years $(S D=9.52)$. The group was made up of employees in diversesized companies, and in public sector organizations. Respondents completed paper-pencil questionnaires.

\section{Table 1}

Means, standard deviations, and intercorrelations for variables under study (Study 1)

\begin{tabular}{lccccc}
\hline Variable & $M$ & $S D$ & 1 & 2 & 3 \\
\hline 1. Procedural justice & 3.44 & 0.79 & $(.83)$ & & \\
2. Acquiescent silence & 3.20 & 1.50 & $-.42^{* *}$ & $(.74)$ & \\
3. Quiescent silence & 3.30 & 1.37 & $-.35^{* *}$ & $.55^{* *}$ & $(.85)$ \\
\hline
\end{tabular}

Note. $N=161 .{ }^{* *} p<.01$. On the diagonal in brackets the Cronbach's $\alpha$ coefficient values are given. 
Krystyna Adamska, Paweł Jurek

Table 2

Means, standard deviations, and intercorrelations for variables under study (Study 2)

\begin{tabular}{lcccccc}
\hline Variable & $M$ & $S D$ & 1 & 2 & 3 & 4 \\
\hline 1. Procedural justice & 2.95 & 0.81 & $(.83)$ & & & \\
2. Interpersonal justice & 4.10 & 0.91 & $.58^{* *}$ & $(.91)$ & & \\
3. Acquiescent silence & 3.47 & 1.76 & $-.44^{* *}$ & $-.24^{* *}$ & $(.84)$ \\
4. Quiescent silence & 3.29 & 1.52 & $-.28^{* *}$ & -.01 & $.64^{* *}$ & $(.84)$ \\
\hline
\end{tabular}

Note. $N=163 .{ }^{* *} p<.01$, two-tailed. On the diagonal in brackets the Cronbach's $\alpha$ coefficient values are given.

Table 3

Summary of results of moderated multiple regression analyses (Study 2)

\begin{tabular}{|c|c|c|c|c|c|c|c|c|}
\hline \multirow[t]{2}{*}{ Predictors } & \multicolumn{4}{|c|}{ Quiescent silence } & \multicolumn{4}{|c|}{ Acquiescent silence } \\
\hline & $B$ & $S E$ & $p$ & $\beta$ & $B$ & $S E$ & $p$ & $\beta$ \\
\hline Procedural justice & -1.07 & .18 & .001 & -.50 & -.84 & .17 & .001 & -.45 \\
\hline Interpersonal justice & -.12 & .16 & .467 & -.06 & .30 & .15 & .048 & .18 \\
\hline $\begin{array}{l}\text { Procedural justice } \times \\
\text { Interpersonal justice }\end{array}$ & -.40 & .11 & .001 & -.28 & -.23 & .10 & .021 & -.19 \\
\hline Adjusted $R^{2}$ & \multicolumn{4}{|c|}{.25} & \multicolumn{4}{|c|}{.13} \\
\hline$\Delta R^{2}$ & \multicolumn{4}{|c|}{.06} & \multicolumn{4}{|c|}{.02} \\
\hline
\end{tabular}

Note. $N=163 . \Delta R^{2}-$ increase in explained variance when model includes the interaction terms.

\section{MEASURES}

Procedural and interpersonal justice. We used the same seven-item scale to measure procedural justice as in the previous study. To measure interpersonal justice, Retowski et al.'s (2107) Polish adaptation of the scale developed by Colquitt (2001) was used. Participants were asked about how they were treated by their managers. The scale included four items such as "Has your supervisor treated you with respect?" and "Has your supervisor treated you with dignity?". Participants rated each item on a five-point scale from 1 (to a very small extent) to 5 (to a very large extent).

Employee self-censorship. The same two subscales were used to measure quiescent and acquiescent silence as in Study 1.

\section{RESULTS}

Table 2 presents the descriptive statistics and intercorrelations among the variables examined in Study 2. The reliability coefficients for each scale are shown on the diagonal.

To test the predictions regarding the main and interaction effects of procedural and interpersonal justice on two motives for employee silence, moderated multiple regression analyses were conducted.
Following the proposal by Aiken and West (1991), predictors were centered, and the interaction term was computed using these scores. Table 3 shows the results of moderated multiple regression analyses.

As can be observed, the results show a significant and negative main effect of procedural justice on both acquiescent and quiescent silence, suggesting that organization members self-censor when they perceive low procedural justice within a workplace. Furthermore, there was no significant main effect of interpersonal justice on acquiescent silence, so self-censorship resulting from resignation does not change in the context of respect and care. Further, quiescent silence was positively predicted by interpersonal justice, suggesting that employees who experience the manifestations of relational ethics are more likely to deliberately withhold concerns, information, or opinions about organizational issues. As expected, the interaction between procedural justice and interpersonal justice was significant and negative for both forms of organizational silence. For a better understanding of the character of the interaction effect revealed in the study, regression slopes for low and high interpersonal justice were drawn (see Figures 1 and 2). As can be seen, the negative relationship between procedural justice and acquiescent and quiescent silence was stronger for organization members who scored higher on interpersonal justice. 


\section{Figure 1}

Acquiescent silence as a function of the interaction between procedural justice and interpersonal justice (Study 2)

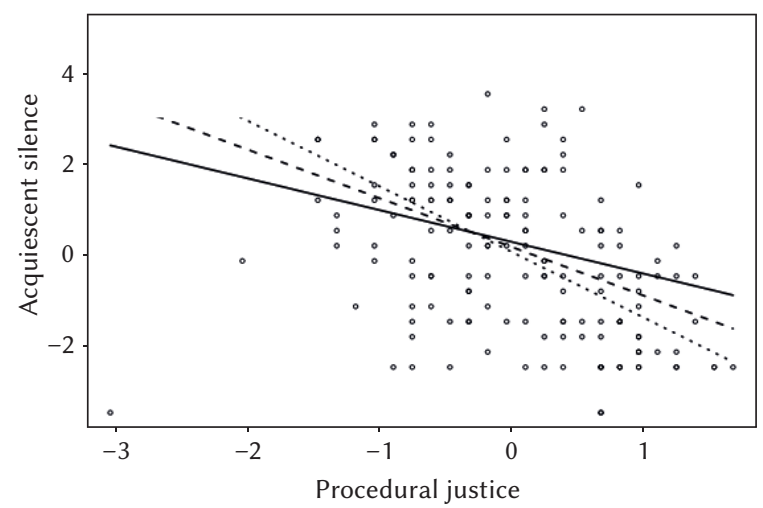

Moderator: Interpersonal justice

$-(\mathrm{m}-\mathrm{sd})$

-.- $(m)$

....... $(\mathrm{m}+\mathrm{sd})$
Figure 2

Quiescent silence as a function of the interaction between procedural justice and interpersonal justice (Study 2)

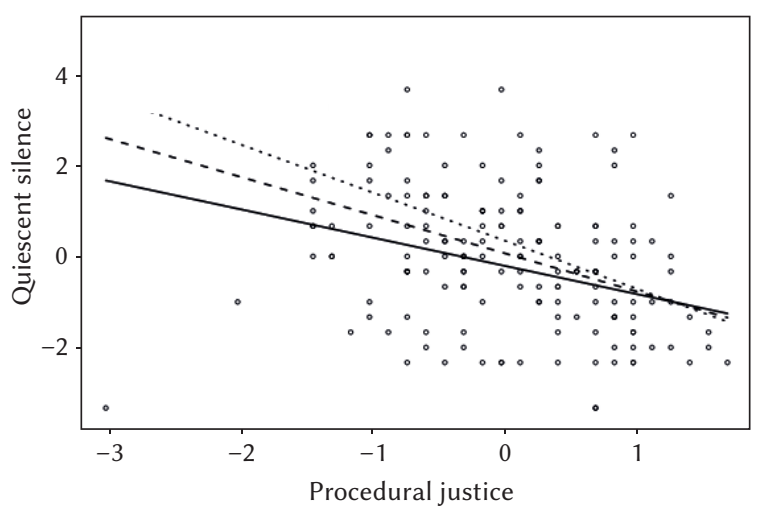

Moderator: Interpersonal justice

$-(\mathrm{m}-\mathrm{sd})$

- - - $(\mathrm{m})$

........ $(m+s d)$

Employee silence beliefs. In order to measure employee silence beliefs, ten items were adopted from Adamska and Retowski's (2012) Verbalization of the Psychological Contract Scale (VPCS). Five of these items measure quiescent silence beliefs in an organization (e.g. "I have experienced the unpleasant consequences of an honest conversation with the boss") and five measure the acquiescent silence beliefs in an organization (e.g. "Superiors hear only what they want to hear"). These items are rated on a sevenpoint scale from 1 (strongly disagree) to 7 (strongly agree).

\section{RESULTS}

Table 4 presents the descriptive statistics and intercorrelations for the variables under study. The reliability coefficients for each scale are shown on the diagonal.
Procedural and interpersonal justice. Both organizational justice dimensions were measured using the same scales as in Study 2.

\section{Table 4}

Means, standard deviations, and intercorrelations for variables under study (Study 3)

\begin{tabular}{lcccccc}
\hline Variable & $M$ & $S D$ & 1 & 2 & 3 & 4 \\
\hline 1. Procedural justice & 3.12 & 0.92 & $(.86)$ & & & \\
2. Interpersonal justice & 3.89 & 0.85 & $.49^{* *}$ & $(.84)$ & & \\
3. Acquiescent silence beliefs & 3.75 & 1.60 & $-.49^{* *}$ & $-.55^{* *}$ & $(.80)$ & \\
4. Quiescent silence beliefs & 3.53 & 1.53 & $-.38^{* *}$ & $-.54^{* *}$ & $.65^{* *}$ & $(.70)$ \\
\hline
\end{tabular}

Note. $N=386 .{ }^{* *} p<.01$. On the diagonal in brackets the Cronbach's $\alpha$ coefficient values are given. 
Krystyna Adamska, Paweł Jurek

Table 5

Summary of results of moderated multiple regression analyses (Study 3)

\begin{tabular}{|c|c|c|c|c|c|c|c|c|}
\hline \multirow[t]{2}{*}{ Predictors } & \multicolumn{4}{|c|}{ Acquiescent silence beliefs } & \multicolumn{4}{|c|}{ Quiescent silence beliefs } \\
\hline & $B$ & $S E$ & $p$ & $\beta$ & $B$ & $S E$ & $p$ & $\beta$ \\
\hline Procedural justice & -.49 & .08 & .001 & -.29 & -.24 & .08 & .001 & -.15 \\
\hline Interpersonal justice & -.80 & .09 & .001 & -.43 & -.87 & .09 & .001 & -.49 \\
\hline $\begin{array}{l}\text { Procedural justice } \times \\
\text { Interpersonal justice }\end{array}$ & -.18 & .08 & .031 & -.09 & -.26 & .08 & .001 & -.14 \\
\hline Adjusted $R^{2}$ & \multicolumn{4}{|c|}{.37} & \multicolumn{4}{|c|}{.32} \\
\hline$\Delta R^{2}$ & \multicolumn{4}{|c|}{.01} & \multicolumn{4}{|c|}{.02} \\
\hline
\end{tabular}

Note. $N=386 . \Delta R^{2}$ - increase in explained variance when model includes the interaction terms.

Figure 3

Acquiescent silence beliefs as a function of the interaction between procedural justice and interpersonal justice (Study 3)

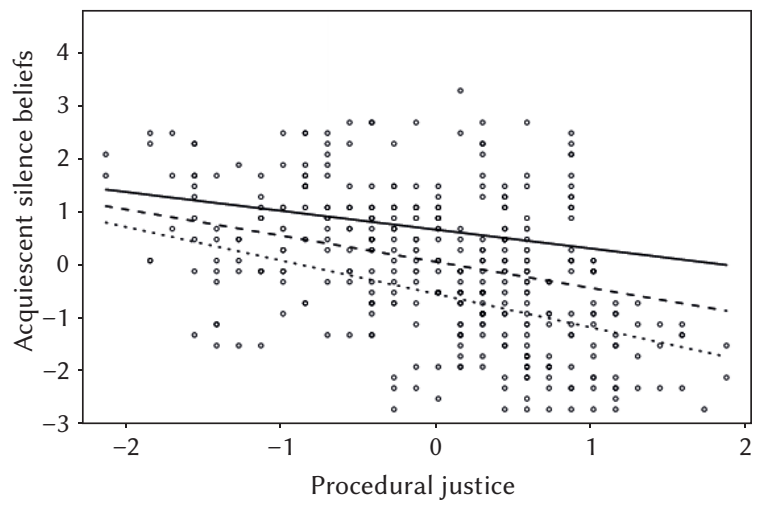

Moderator: Interpersonal justice

$-(\mathrm{m}-\mathrm{sd})$

- - - $(\mathrm{m})$

....... $(m+s d)$

In order to test the predictions regarding the main and the interaction effects of procedural and interpersonal justice on acquiescent and on quiescent silence beliefs, moderated multiple regression analyses were run. As in the previous study, in order to compute the interaction term, predictors were centered. A summary of the results of these analyses is presented in Table 5 .

The results of moderated multiple regression analyses showed a significant negative main effect of procedural justice on both acquiescent and quiescent silence beliefs, suggesting that when an organization's members perceive low procedural justice in the workplace, they are more convinced that their work environment abounds in silence factors. In line with our expectations, there was a significant negative main effect of interpersonal justice on acquiescent and quiescent silence beliefs, suggesting that
Figure 4

Quiescent silence beliefs as a function of the interaction between procedural justice and interpersonal justice (Study 3)

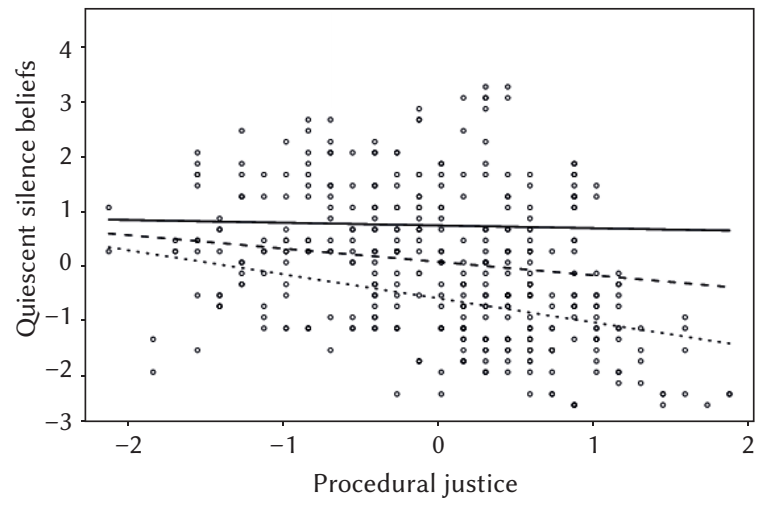

Moderator: Interpersonal justice

$-(\mathrm{m}-\mathrm{sd})$

$-\cdot-(m)$

..... $(\mathrm{m}+\mathrm{sd})$

employees with low expectations of interpersonal justice in an organization are more inclined to believe that relations within the organization do not encourage people to speak up. As expected, the interaction between procedural justice and interpersonal justice was significant and negative for both acquiescent and quiescent silencing belief. Figures 3 and 4 show regression slopes for low and high interpersonal justice. These figures shows that the negative relationships between procedural justice and acquiescent and quiescent silence beliefs were stronger for employees who perceive interpersonal justice relatively highly.

\section{DISCUSSION}

We tested in our study the role of interaction of procedural justice and interpersonal justice in reduc- 
ing self-censorship, understood as the decision to withdraw from speaking, and in reducing employee silence beliefs with regard to specific observations and experiences in the current place of employment. It was found that when employees highly evaluate procedural justice, they declare less self-censorship motivated by fear and resignation (see Study 1). Additionally, the results showed that in high interpersonal justice conditions the role of procedural justice in predicting employee self-censorship (Study 2) as well as employee silence beliefs (Study 3) increases. Our study confirms the results obtained by Tangirala and Ramanujam (2008) that with more procedural justice, there is less silence, and also supports the claim of Wilkinson and colleagues (2010) that formal mechanisms of procedural justice are effective particularly when managers treat their subordinates with respect.

It was also revealed that self-censorship motivated by fear of consequences (quiescent silence) was positively predicted by interpersonal justice, while there was no relation between self-censorship motivated by resignation (acquiescent silence) and interpersonal justice. These results can be explained by referring to the broader context of ethics in which procedural justice and interpersonal justice are immersed. Procedural justice represents the ethics of justice, while interpersonal justice is based on the ethics of relation and care. A focus on relationships in the absence of the ethics of justice is associated with a reluctance to disrupt them, which can happen when there is open communication about perceived irregularities (Gilligan, 1982). It is far from easy to report wrong-doings (Jeffries \& Hornsey, 2012; Near \& Miceli, 1985), to share information with others that may contradict their beliefs (Reimer et al., 2010) or to expose oneself to the danger of exclusion by being treated as a troublemaker (Miceli et al., 2009; NoelleNeumann, 1993).

Thus our results confirm the idea expressed by Paley (2002) that ethics of justice is a guard of an ethics of care when "it has gone too far", that is when caring about relationships leads to self-censorship on issues that need to be changed. This is the case only when an employee's decision is dictated by negative emotions (quiescence silence) but not when self-censorship is motivated by resignation (acquiescence silence). Resignation is a mental state devoid of emotions mainly due to the fact that previous efforts to change the situation have proved ineffective, so the decision to keep silence is a rational conclusion drawn on the basis of experience (Morrison \& Milliken, 2000). Active and defensive quiescence silence (Pinder \& Harlos, 2001; Van Dyne et al., 2003) is an inner state which could be more susceptible to relational aspects of contacts with supervisors than to the importance of substantive objections to certain events and wrongdoings in the organization, includ- ing behaviors of the supervisor. While this may be a speculative interpretation of the results obtained, it could nonetheless be supported by concepts related to the role of emotions in speaking up (Grant, 2012) and theories and research on group integrity (Esposo et al., 2013; Packer, 2014).

Our study was based on the supposition that ethics of justice and relational ethics complement each other in the domain of self-censorship, and the results duly confirm this theoretical expectation. Respect and concern for relationships under conditions of high procedural fairness reduces self-censorship. Additional studies are necessary to verify this conclusion. Our study should also be developed to explore more effectively the subjective aspect of procedural justice. The participants of the study judged procedural justice in their organizations and were not differentiated according to their susceptibility to justice. It may be the case that those with a pronounced awareness of the sense and meaning of procedural justice are responsible for the strong negative correlation between procedural justice and self-censorship. This line of reasoning is supported by studies on the relation between the need for autonomy and procedural justice: those who are deprived of autonomy are also more sensitive to the manner in which authority figures treat them (van Prooijen, 2009). Likewise, lower status could lead to increased cognitive accessibility of fairness (van Prooijen et al., 2002).

One further aspect of the link between interaction of the two types of ethics and self-censorship calls for scrutinization, that is the climate of silence: a socially shared belief about the sense of influencing the situation through voice (Morrison et al., 2011; Perlow \& Repenning, 2009). This belief is rooted in the informal set of rules which regulates communication behaviors. Although our study has partly addressed this aspect by measuring employee silence beliefs, our focus was on individual rather than shared beliefs; hence the latter can only be presumed. There is also an important contextual factor related to shared beliefs, namely national culture. Cultural differences should be included in future studies since the meaning and function of silence varies between individualistic and collectivistic cultures (Botero \& Van Dyne, 2009; Covarrubias, 2007; Kawabata \& Gastaldo, 2015; Morrison et al., 2004; St. Clair, 2003). The control of emotions through acts of suppression has negative psychological effects in countries with more individualistic cultures, while no such relationship occurs in collectivistic countries (Ford \& Mauss, 2015). As self-censorship requires the suppression of emotions in response to negative events in the organizational environment, it may be beneficial if cultural values are controlled in future studies in order to determine whether the strengthening of procedural fairness with interpersonal justice is a universal factor, irrespective of culture, in the reduction of self-censorship. 


\section{References}

Adamska, K. (2017). Self-censorship in organizations. In D. Bar-Tal, R. Nets-Zehngut, \& K. Sharvit (Eds.), Self-censorship in contexts of conflict: Theory and research (pp. 41-60). Springer International Publishing.

Adamska, K., \& Jurek, P. (2017). Adaptation of the Four Forms of Employee Silence Scale in a Polish sample. Current Issues in Personality Psychology, 5, 1-10. https://doi.org/10.5114/cipp.2017.68335

Adamska, K., \& Retowski, S. (2012). Verbalization of the psychological contract: a diagnostic tool. In M. Lipowski \& Z. Nieckarz (Eds.), Empirical aspects of the psychology of management (pp. 58-97). Wyższa Szkoła Administracji i Biznesu w Gdyni.

Aiken, L. S., \& West, S. G. (1991). Multiple regression: Testing and interpreting interactions. Sage Publications.

Allen, S. (2013). An interpretation of care and justice through the concepts of a Kantian \& Confucian ethic. Retrieved from https://www.academia. edu/11638319/An_Interpretation_of_Care_and_ Justice_through_the_concepts_of_a_Kantian_ and_Confucian_Ethic

Argyris, C., \& Schon, D. (1978). Organisational learning: A theory of action perspective. Addison Wesley.

Bauman, C. W., \& Skitka, L. J. (2009). Moral disagreement and procedural justice: Moral mandates as constraints to voice effects. Australian Journal of Psychology, 61, 40-49. https://doi.org/ 10.1080/00049530802607647

Bar-Tal, D., Nets-Zehngut, R., \& Sharvit, K. (Eds.) (2017). Self-censorship in contexts of conflict: Theory and research. Springer International Publishing.

Beer, M., \& Eisenstat, R. E. (2000). The silent killers of strategy implementation and learning. MIT Sloan Management Review, 41, 29-40.

Blader, S. L., \& Tyler, T. R. (2009). Testing and extending the group engagement model: Linkages between social identity, procedural justice, economic outcomes and extra-role behavior. Journal of Applied Psychology, 94, 445-464. https://doi. org/10.1037/a0013935

Botero, I. C., \& Van Dyne, L. (2009). Employee voice behavior. Interactive effects of LMX and power distance in the United States and Colombia. Management Communication Quarterly, 23, 84-104. https://doi.org/10.1177/0893318909335415

Botes, A. (2001). A comparison between the ethics of justice and the ethic of care. Journal of Advanced Nursing, 32, 1071-1075. https://doi.org/10.1046/j. 1365-2648.2000.01576.xC

Brebels, L., De Cremer, D., Sedikides, C., \& Van Hiel, A. (2013). Self-focus and procedural fairness: The role of self-rumination and self-reflection. Social Justice Research, 26, 151-167. https://doi.org/10.1007/ s11211-013-0180-4
Chen, Y., Brockner, J., \& Greenberg, J. (2003). When is it a "pleasure to do business with you?" The effects of status, outcome favorability, and procedural fairness. Organizational Behavior and Human Decision Processes, 92, 1-21. https://doi.org/10.1016/ S0749-5978(03)00062-1

Cohen-Charash, Y., \& Spector, P. E. (2001). The role of justice in organizations: a meta-analysis. Organizational Behavior and Human Decision Processes, 86, 278-321. https://doi.org/10.1006/obhd.2001.2958

Colquitt, J. A. (2001). On the dimensionality of organizational justice: a construct validation of a measure. Journal of Applied Psychology, 86, 386-400. https://doi.org/10.1037//0021-9010.86.3.386

Colquitt, J. A., Conlon, D. E., Wesson, M. J., Porter, Ch., \& Ng, K.Y. (2001). Justice at the millennium: a metaanalytic review of 25 years of organizational justice research. Journal of Applied Psychology, 86, 425445. https://doi.org/10.1037//0021-9010.86.3.425

Colquitt, J. A., \& Rodell, J. B. (2015). Measuring justice and fairness. In R. S. Cropanzano \& M. L. Ambrose (Eds.), The Oxford handbook of justice in the workplace (pp. 187-202). Oxford University Press.

Cortina, L. M., \& Magley, V. J. (2003). Raising voice, risking retaliation: Events following interpersonal mistreatment in the workplace. Journal of Occupational Health Psychology, 8, 247-265. https://doi. org/10.1037/1076-8998.8.4.247

Covarrubias, P. (2007). (Un)Biased in Western theory: Generative silence in American Indian communication. Communication Monographs, 74, 265-271. https://doi.org/10.1080/03637750701393071

Creed, W. E. D., Hudson, B. A., Okhuysen, G. A., \& Smith-Crowe, K. (2014). Swimming in a sea of shame: Incorporating emotion into explanations of institutional reproduction and change. Academy of Management Review, 39, 275-301. https://doi. org/10.5465/amr.2012.0074

De Cremer, D., \& Sedikides, C. (2005). Self-uncertainty and responsiveness to procedural justice. Journal of Experimental Social Psychology, 41, 157-173. https://doi.org/10.1016/j.jesp.2004.06.010

Detert, J. R., \& Edmondson, A. C. (2011). Implicit voice theories: Taken-for-rules of self-censorship at work. Academy of Management Journal, 54, 461-488. https://doi.org/10.5465/AMJ.2011.61967925

Donaghey, J., Cullinane, N., Dundon, T., \& Wilkinson, A. (2011). Reconceptualizing employee silence: Problems and prognosis. Work, Employment \& Society, 25, 51-67. https://doi.org/10.1177/0950017010389239

Esposo, S. R., Hornsey, M. J., \& Spoor, J. R. (2013). Shooting the messenger: Outsiders critical of your group are rejected regardless of argument quality. British Journal of Social Psychology, 52, 386-395. https://doi.org/10.1111/bjso.12024

Fast, N. J., Burris, E. R., \& Bartel, C. A. (2014). Managing to stay in the dark: Managerial self-efficacy, ego defensiveness, and the aversion to employee 
voice. Academy of Management Journal, 57, 10131034. https://doi.org/10.5465/amj.2012.0393

Folger, R. (1977). Distributive and procedural justice: Combined impact of "voice" and improvement on experienced inequity. Journal of Personality and Social Psychology, 35, 108-119. https://doi.org/ 10.1037/0022-3514.35.2.108

Ford, B. Q., \& Mauss, I. B. (2015). Culture and emotion regulation. Current Opinion in Psychology 3, 1-5. https://doi.org/10.1016/j.copsyc.2014.12.00

Gao, L., Janssen, O., \& Shi, K. (2011). Leader trust and employee voice: The moderating role of empowering leader behaviors. The Leadership Quarterly, 22, 787798. https://doi.org/10.1016/j.leaqua.2011.05.015

Gilligan, C. (1982). In a different voice: Psychological theory and women's development. Harvard University Press.

Gilligan, C. (2006). From in a different voice to the birth of pleasure: an intellectual journey. North Dakota Law Review, 81, 729.

Grant, A. M. (2012). Rocking the boat but keeping it steady: The role of emotion regulation in employee voice. The Academy of Management Journal, 56, 1703-1723. https://doi.org/10.5465/amj.2011.0035

Greenberg, J. (1993). The social side of fairness: Interpersonal and informational classes of organizational justice. In R. Cropanzano (Ed.), Justice in the workplace: Approaching fairness in human resource management (pp. 79-103). Erlbaum.

Hamington, M. (2011). Care ethics, knowledge management, and the learning organization. In M. Hamington \& M. Sander-Staudt (Eds.), Applying care ethics to business (pp. 245-258). Springer.

Hamington, M. (2019). Integrating care ethics and design thinking. Journal of Business Ethics, 155, 91-103. https://doi.org/10.1007/s 10551-017-3522-6

Hirak, R., Peng, A. C., Carmeli, A., \& Schaubroeck, J. M. (2012). Linking leader inclusiveness to work unit performance: The importance of psychological safety and learning from failures. The Leadership Quarterly, 23, 107-117. https://doi.org/10.1016/j. leaqua.2011.11.009

Holmvall, C. M., \& Bobocel, D. R. (2008). What fair procedures say about me: Self-construals and reactions to procedural fairness. Organizational Behavior and Human Decision Processes, 105, 147-168. https://doi.org/10.1016/j.obhdp.2007.09.001

Jeffries, C. H., \& Hornsey, M. J. (2012). Withholding negative feedback: Is it about protecting the self or protecting others? British Journal of Social Psychology, 51, 772-780. https://doi.org/10.1111/j. 2044-8309.2012.02098

Judge, T. A., \& Colquitt, J. A. (2004). Organizational justice and stress: The mediating role of work-family conflict. Journal of Applied Psychology, 89, 395404. https://doi.org/10.1037/0021-9010.89.3.395

Kawabata, M., \& Gastaldo, D. (2015). The less said, the better: Interpreting silence in qualitative research.
International Journal of Qualitative Methods, 14, 1-9. https://doi.org/10.1177/1609406915618123

Kish-Gephart, J. J., Detert, J. R., Trevino, L. K., \& Edmondson, A. C. (2009). Silenced by fear: The nature, sources, and consequences of fear at work. Research in Organizational Behavior, 29, 163-193. https://doi.org/10.1016/j.riob.2009.07.002

Knoll. M., \& van Dick, R. (2013). Do I hear the whistle...? A first attempt to measure four forms of employee silence and their correlates. Journal of Business Ethics, 113, 349-362. https://doi.org/10.1007/ s10551-012-1308-4

Knoll, M., Neves, P., Schyns, B., \& Meyer, B. (2021). A multi-level approach to direct and indirect relationships between organizational voice climate, team manager openness, implicit voice theories, and silence. Applied Psychology, 70, 606-642. https://doi.org/10.1111/apps. 12242

Knoll, M., Wegge, J., Unterrainer, C., Silva, S., \& Jønsson, T. (2016). Is our knowledge of voice and silence in organizations growing? Building bridges and (re) discovering opportunities. German Journal of Human Resource Management, 30, 161-194. https://doi.org/10.1177/2397002216649857

Lee, F. (1993). Being polite and keeping MUM: How bad news is communicated in organizational hierarchies. Journal of Applied Social Psychology, 23, 1124-1149. https://doi.org/10.1111/j.1559-1816. 1993.tb01025.x

LePine, J. A., \& Van Dyne, L. (2001). Voice and cooperative behavior as contrasting forms of contextual performance: Evidence of differential relationships with Big Five personality characteristics and cognitive ability. Journal of Applied Psychology, 86, 325336. https://doi.org/10.1037//0021-9010.86.2.326

LeRoy, J., Bastounis, M., \& Minibas-Poussard, J. (2012). Interactional justice and counterproductive work behaviors: The mediating role of negative emotions. Social Behaviour and Personality, 40, 13411356. https://doi.org/10.2224/sbp.2012.40.8.1341

Metz, T., \& Miller, S. C. (2016). Relational ethics. In $\mathrm{H}$. LaFollette (Ed.), The international encyclopedia of ethics (pp. 1-10). Wiley-Blackwell.

Miceli, M. P., Near, J. P., \& Dworkin, T. M. (2009). A word to the wise: How managers and policymakers can encourage employees to report wrongdoing. Journal of Business Ethics, 86, 379-396. https://doi.org/10.1007/s10551-008-9853-6

Morrison, E. W. (2014). Employee voice and silence. Annual Review of Organizational Psychology and Organizational Behavior, 1, 173-197. https://doi. org/10.1146/annurev-orgpsych-031413-091328

Morrison, E. W., Chen, Y. R., \& Salgado, S. R. (2004). Cultural differences in newcomer information seeking: a comparison of the United States and Hong Kong. Applied Psychology: An International Review, 53, 1-22. https://doi.org/10.1111/j.14640597.2004.00158.x 
Morrison, E. W., \& Milliken, F. J. (2000). Organizational silence: a barrier to change and development in a pluralistic world. Academy of Management Review, 25, 706-725. https://doi.org/10.2307/259200

Morrison, E. W., Wheeler-Smith, S. L., \& Kamdar, D. (2011). Speaking up in groups: a cross-level study of group voice climate and voice. Journal of Applied Psychology, 96, 183-191. https://doi.org/10.1037/ a0020744

Near, J. P., \& Miceli, M. P. (1985). Organizational dissidence: The case of whistle-blowing. Journal of Business Ethics, 4, 1-16. https://doi.org/10.1007/ BF00382668

Nechanska, E., Hughes, E., \& Dundon, T. (2020). Towards an integration of employee voice and silence. Human Resource Management Review, 30, 100674. https://doi.org/10.1016/j.hrmr.2018.11.002

Noelle-Neumann, E. (1993). The spiral of silence: Public opinion, our social skin. University of Chicago Press.

Overbeck, J. R., Tiedens, L. Z., \& Brion, S. (2006). The powerful want to, the powerless have to: Perceived constraint moderates causal attributions. European Journal of Social Psychology, 36, 479496. https://doi.org/10.1002/ejsp.353

Packer, D. J. (2014). On not airing our dirty laundry: Intergroup contexts suppress ingroup criticism among strongly identified group members. British Journal of Social Psychology, 53, 93-111. https://doi. org/10.1111/bjso. 12017

Paley J. (2002). Caring as a slave morality: Nietzschean themes in nursing ethics. Journal of Advanced Nursing, 40, 25-44. https://doi.org/10.1046/j.13652648.2002.02337.x

Perlow, L. A., \& Repenning, N. P. (2009). The dynamics of silencing conflict. Research in Organizational Behaviour, 29, 195-223. https://doi.org/10.1016/j. riob.2009.06.007

Perlow, L. A., \& Williams, S. (2003). Is silence killing your company? Harvard Business Review, 81, 52-58.

Pinder, C., \& Harlos, K. (2001). Employee silence: Quiescence and acquiescence as responses to perceived injustice. In G. Ferris (Ed.), Research in personnel and human resources management (pp. 331-369). JAI Press.

Pollard, C. (2015). What is the right thing to do: Use of a relational ethic framework to guide clinical decision-making. International Journal of Caring Sciences, 8, 362-368.

Rawls, J. (1999). The theory of justice. Oxford University Press.

Reimer, T., Reimer, A., \& Czienskowski, U. (2010). Decision-making groups attenuate the discussion bias in favor of shared information: a meta-analysis. Communication Monographs, 77, 121-142. https://doi.org/10.1080/03637750903514318

Rego, A., \& Pina a Cunha, M. (2010). Organizational justice and citizenship behaviors: a study in the
Portuguese cultural context. Applied Psychology: An International Review, 59, 404-430. https://doi. org/10.1111/j.1464-0597.2009.00405.x

Retowski, S., Adamska, K., \& Konarski, R. (2017). More justice in Polish organizations, but only for men. $\mathrm{Pa}-$ per presented at EAWOP, Dublin, May 17-20, 2017.

Rumsey, J. P. (1997). Justice, care, and questionable dichotomies. Hypatia, 12, 99-113. https://doi.org/ 10.1111/j.1527-2001.1997.tb00173.x

Sandel, M. (1998). Liberalism and the limits of justice. Cambridge University Press.

Sedikides, C., \& Gregg, A. P. (2008). Self-enhancement: Food for thought. Perspectives on Psychological Science, 3, 102-116. https://doi.org/10.1111/ j.1745-6916.2008.00068.x

Skitka, L. J. (2003). Of different minds: an accessible identity approach to why and how people think about justice. Personality and Social Psychology Review, 7, 286-297. https://doi.org/10.1207/S153279 57PSPR0704_02

St. Clair, R. (2003). The social and cultural construction of silence. Intercultural Communication Studies, 12, 87-91.

Tahmasebi, F., Sobhanipour, S. M., \& Aghaziarati, M. (2013). Burnout: Explaining the role of organizational silence and its influence (case study: selected executive organizations of Qom Province). Journal of Basic and Applied Scientific Research, 3, 272-282.

Tangirala, S., \& Ramanujam, R. (2008). Employee silence on critical work issues: The cross-level effects of procedural justice climate. Personnel Psychology, 61, 37-68. https://doi.org/10.1111/j.17446570.2008.00105.x

Tushman, M., \& Nadler, D. (1978). Information processing as an integrating concept in organizational design. Academy of Management Review, 3, 613-624. https://doi.org/10.5465/amr.1978.4305791

Tyler, T. R., \& Lind, E. A. (1992). A relational model of authority in groups. In M. Zanna (Ed.), Advances in experimental social psychology (pp. 595-629). McGraw-Hill.

Thibaut, J., \& Walker, L. (1975). Procedural justice: a psychological analysis. Erlbaum.

Van den Bos, K., \& Lind, E. A. (2010). The social psychology of fairness and the regulation of personal uncertainty. In R. M. Arkin, K. C. Oleson, \& P. J. Carroll (Eds.), The uncertain self: a handbook of perspectives from social and personality psychology (pp. 122-141). Psychology Press.

Van Dyne, L., Ang, S., \& Botero, I. C. (2003). Conceptualizing employee silence and employee voice as multidimensional constructs. Journal of Management Studies, 40, 1359-1392. https://doi.org/ 10.1111/1467-6486.00384

van Prooijen, J. W. (2009). Procedural justice as autonomy regulation. Journal of Personality and Social Psychology, 96, 1166-1180. https://doi.org/10.1037/ a0014153 
van Prooijen, J. W., van den Bos, K., \& Wilke, H. A. M. (2002). Procedural justice and status: Status salience as antecedent of procedural fairness effects. Journal of Personality and Social Psychology, 83, 13531361. https://doi.org/10.1037/0022-3514.83.6.1353

van Prooijen, J. W., \& Zwenk, F. (2009). Self-construal level and voice procedures: The individual self as psychological basis for procedural fairness effects. Journal of Experimental Social Psychology, 45, 392397. https://doi.org/10.1016/j.jesp.2008.10.008

Wenzel, M. (2000). Justice and identity: The significance of inclusion for perceptions of entitlement and the justice motive. Personality and Social Psychology Bulletin, 26, 157-176. https://doi. org/10.1177/0146167200264004

Wiener, N. (1950). On human use of human beings. Cybernetics and society. Eyre \& Spottiswoode.

Wilkinson, A., \& Dundon, T. (2017). Employee involvement and participation. In A. Wilkinson, T. Redman, \& T. Dundon (Eds.), Contemporary human resource management (5th ed.) (pp. 402-428). Pearson Education Limited.

Wilkinson, A., Gollan, P., Marchington, M., \& Lewin, D. (2010). Conceptualizing employee participation in organizations. In A. Wilkinson, P. Gollan, M. Marchington, \& D. Lewin (Eds.), The Oxford handbook of employee participation in organizations (pp. 4-25). Oxford University Press.

Zill, A., Knoll, M., Cook, A., \& Meyer, B. (2020). When do followers compensate for leader silence? The motivating role of leader injustice. Journal of Leadership \& Organizational Studies, 27, 65-79. https:// doi.org/10.1177/1548051818820861 